\title{
Using Acid-Activated Azad Kashmir Clays to Remove Cadmium and Lead Ions from Wastewater
}

\author{
Nadia Ayub ${ }^{1 *}$, Abdul Mannan Ehsan², Muhammad Nawaz Chaudhry ${ }^{3}$ \\ ${ }^{1}$ College of Earth and Environmental Sciences, University of the Punjab, Lahore, Pakistan \\ ${ }^{2}$ Pakistan Council of Scientific and Industrial Research Labs, Lahore, Pakistan \\ ${ }^{3}$ Department of Environmental Science and Policy, Lahore School of Economics, Pakistan
}

Received: 6 August 2019

Accepted: 21 November 2019

\begin{abstract}
The adsorption of cadmium and lead ions on purified and acid-activated Azad Kashmir clays were investigated in a batch system. Solutions of lead and cadmium having concentrations typically found in industrial wastewater were used to develop a cheap and reliable adsorbent using local clay for removal of heavy metals from wastewater. The raw clay sample was purified and activated by sulphuric acid before being used for adsorption study. It was characterized by X-ray diffraction and chemical analysis according to the International Standards of Testing (ASTM C 323-56, 2016). The effects of factors like $\mathrm{pH}$, adsorbent quantity, concentration of adsorbate and temperature were studied for both metals. The Langmuir and Freundlich models were used for analysis of adsorption equilibrium. Thermodynamic parameters were calculated. Azad Kashmir clay removed lead and cadmium with maximum adsorption capacity of $3.93 \mathrm{mg}$ metal/g and $7.81 \mathrm{mg}$ metal/g of clay $\left(30^{\circ} \mathrm{C}\right.$; $\left.\mathrm{pH} 7.3\right)$. These values were calculated by applying Langmuir and Freundlich adsorption isotherms to the actual experimental results obtained in this study. The thermodynamic data indicated that the adsorption reaction for cadmium is spontaneous and exothermal while it is endothermic for lead. The Freundlich model provided best fit for sorption isotherms for both cadmium and lead.
\end{abstract}

Keywords: cadmium, Freundlich and Langmuir isotherms, lead, Montmorillonite clay, wastewater

\section{Introduction}

Industrial waste, raw sewage and agricultural runoff continue to pollute surface and groundwater sources across Pakistan [1]. It has been widely recognized that agricultural, urban and industrial waste containing

*e-mail: nadia.ayub85@gmail.com contaminants such as dyes, fertilizers, pesticides and heavy metals deteriorate the quality of water. This can result in severe damage to human health, aquatic habitats and species. Due to their toxicity, heavy metals have been acknowledged as major pollutants. They have a tendency to easily accumulate in the soft tissues and are not metabolized or broken down by the body [2]. Heavy metals are non-biodegradable unlike organic pollutants, are inorganic and can easily travel along 
the food chain through bioaccumulation [3]. An estimated annual national income loss of Rs. 25-58 billion and over 250,000 deaths in children in Pakistan are reported every year due to diarrheal diseases alone. Almost $20-40 \%$ of the hospital beds in the country are occupied by patients suffering from water-borne diseases that result in one-third of all mortalities [4].

There is an increased likelihood of huge quantities of wastewater contaminated with heavy metals being discharged by industries involving the application of heavy metals such as chromium (Cr), arsenic (As), cadmium $(\mathrm{Cd})$, lead $(\mathrm{Pb})$, nickel $(\mathrm{Ni})$, zinc $(\mathrm{Zn})$ and copper $(\mathrm{Cu})$. Such effluents are considered to be more harmful in comparison with chemical-intensive industries [5]. Toxic pollutants such as lead and cadmium are released in the environment from various sources, including agricultural runoff, paint industries and mining operations [6]. Various industries, including electro-plating, textile, storage batteries, metal plating, steel and leather manufacturing units discharge wastewater contaminated with high concentrations of toxic heavy metals such as lead, cadmium, nickel, chromium, and copper [7].

Lead present in the environment in excess amounts can possibly pose long-term threats to ecosystems and human health. Lead, an industrial pollutant, can easily enter the ecosystem through water, air and soil, and being a systemic toxicant can result in kidney malfunction, tissue damage of brain, anaemia, and even death in high dosage amounts. It is extremely toxic [5].

Due to severe toxicity and harmful effects on the health of both flora and fauna, cadmium is considered to be a major pollutant. The allowable limit of cadmium in water is $0.003 \mathrm{mg} / \mathrm{L}$ according to the guidelines provided by the World Health Organization. Kidneys are considered to be the main target organ for cadmium [8].

The imbalanced economic and social development in recent decades has aggravated the environmental challenges of Pakistan [4]. Due to high wastewater treatment costs, only a small fraction of wastewater is being treated (less than 1\%) by industries and direct disposal of untreated wastewater into fresh water resources is a common practice. Industrial expansion exerts significant pressure on water resources and has increased water pollution problems. In order to supply sufficient outputs to meet the demands of the increasing global population, remediation of environmental contaminants is a great challenge for these industries [1].

Various techniques including reverse osmosis, chemical precipitation, ion exchange and electrolysis have already been developed for the removal of heavy metals from wastewater [9]. These include bio-adsorption, ion exchange, adsorption, biological treatment, coagulation, reverse osmosis, electrocoagulation, chemical precipitation, membrane filtration and solvent extraction [10]. The limitations for most of the complex processes include high implementation and maintenance costs. Furthermore, some methods can be inappropriate or ineffective for effluents containing low concentrations of metals [11]. The process of adsorption to remove heavy metal ions from wastewaters is widely used owing to its efficiency and low cost [12].

Clays and their modified forms are efficient adsorbents for various heavy metals [13]. Naturally occurring clays such as monmorillonite have a high surface area, cationic exchange capacity and micro- and mesoporosity [14].

Clays are naturally abundant, inexpensive and environmentally friendly with high mechanical and chemical stability in addition to possesing large specific surface area and high cation exchange capacity. These properties of clays can be further enhanced by treatment with concentrated inorganic acids. This process is usually referred to as acid activation [13]. Acid-treated clay shows a higher adsorption capacity as compared to its non-modied and raw form [15].

Bentonite clay deposits are abundantly found at various places across Pakistan. Reasonably big deposits occur near Mirpur (Azad Kashmir) [16].

This study aims to evaluate the adsorption characteristics of locally available Azad Kashmir montmorillonite clays by subsequent acid-activation for the elimination of cadmium and lead from waste and natural waters.

\section{Materials and Methods}

\section{Materials and Reagents}

Analytical grade chemicals were used in this study. Double-distilled water was used for preparation of all standards and dilutions. The standard solutions of employed elements were prepared by diluting the 1000 parts-per million (ppm) stock solution supplied by Sigma and Aldrich.

\section{Instruments}

A Hitachi Z-8000 atomic absorption spectrometer was used. All measurements were taken in air/acetylene flame. The operating parameters were set according to the manufacturer guidelines. A Sartorius pp-15 model glass-electrode $\mathrm{pH}$ meter was used to measure the $\mathrm{pH}$ values of the solutions.

\section{Characterization of Clay}

Montmorillonite clay of Azad Kashmir, Pakistan origin was acquired from the Azad Kashmir Mineral Development Corporation (AKMDC). It was washed, purified and then a standard procedure of sedimentation was applied to obtain a $<2 \mu \mathrm{m}$ fraction of clay. The characterization of clay was carried out by chemical analysis, cation exchange capacity and $\mathrm{x}$-ray diffraction 
(X-RD) analysis [17]. The chemical analysis was performed according to the international standards of testing procedures prescribed in ASTM C 323-56, 2016, for Loss on Ignition $\left(950^{\circ} \mathrm{C}\right), \mathrm{SiO}_{2}, \mathrm{Al}_{2} \mathrm{O}_{3}, \mathrm{Fe}_{2} \mathrm{O}_{3} \mathrm{CaO}$, $\mathrm{MgO}, \mathrm{Na}_{2} \mathrm{O}$ and $\mathrm{K}_{2} \mathrm{O}$.

\section{Acid Activation of Clay}

The less than $2 \mu \mathrm{m}$ clay was acid-activated by slowly adding concentrated sulphuric acid to clay water slurry in a beaker with constant stirring for a period of 3 hours. After that, the clay acid mixture was kept for 24 hours at room temperature. This was followed by filtration and washing several times with distilled water until the $\mathrm{pH}$ of the filtrate became neutral [18]. After these processes, the clay was dried, ground and subsequently sieved through a sieve of 200 mesh size.

\section{Batch Adsorption Experiments}

Individual batch adsorption experiments for each element were carried out on a shaker at room temperature $\left(30^{\circ} \mathrm{C}\right)$. In $100 \mathrm{ml}$ conical flasks covered with cork, the standard solution of particular elements cadmium (II) and lead (II) were taken (i.e., 2.0 grams of adsorbent and $50 \mathrm{ml}$ of standard solution). After agitation, the suspensions were filtered and the filtrate was analysed using atomic absorption spectrophotometry. Different experiments were carried out by varying the weight of adsorbent, initial concentration and temperature to assess the performance of the adsorbent.

\section{Results and Discussion}

\section{Characterization of Clay}

The chemical analysis for raw, purified and acidactivated clay is given in Table 1 . There is a marked

Table 1. Chemical analysis of raw, purified and acid-activated Azad Kashmir clay.

\begin{tabular}{|c|c|c|c|c|}
\hline $\begin{array}{c}\mathrm{Sr} \\
\text { No. }\end{array}$ & Element & $\begin{array}{c}\text { Raw Clay } \\
\% \text { age }\end{array}$ & $\begin{array}{c}\text { Purified Clay } \\
\% \text { age }\end{array}$ & $\begin{array}{c}\text { Acid- Activated } \\
\text { Clay } \\
\% \text { age }\end{array}$ \\
\hline 1 & $\begin{array}{c}\text { Loss on } \\
\text { Ignition }\end{array}$ & 12.00 & 9.38 & 7.40 \\
\hline 2 & $\mathrm{SiO}_{2}$ & 63.58 & 52.00 & 61.56 \\
\hline 3 & $\mathrm{Al}_{2} \mathrm{O}_{3}$ & 14.62 & 24.50 & 21.80 \\
\hline 4 & $\mathrm{Fe}_{2} \mathrm{O}_{3}$ & 2.05 & 3.00 & 1.50 \\
\hline 5 & $\mathrm{CaO}^{2}$ & 5.58 & 7.81 & 4.20 \\
\hline 6 & $\mathrm{MgO}^{2}$ & 1.52 & 2.80 & 3.03 \\
\hline 7 & $\mathrm{Na}_{2} \mathrm{O}$ & 0.75 & 0.38 & 0.42 \\
\hline 8 & $\mathrm{~K}_{2} \mathrm{O}$ & 0.25 & 0.11 & 0.08 \\
\hline
\end{tabular}

decrease in the content of $\mathrm{SiO}_{2}$ in purified clay due to the removal of free silica from the clay. The alumina content is increased, indicating an increase in montmorillonite content. The oxides of aluminium, calcium, and magnesium show properties of montmorillonite and play an important role in the adsorption of cations. The sedimentation process increases the aluminium content from $14.62 \%$ (raw clay) to $24.50 \%$ (purified form). However, after acid-activation of this purified clay, these aluminium ions are reduced to $21.80 \%$. This might have resulted due to partial dissolution of the octahedral layer ( $\mathrm{Al}, \mathrm{Fe}, \mathrm{Mg}-\mathrm{O}$ layers) and the exposure of the tetrahedral layers ( $\mathrm{Si}-\mathrm{O}$ layers) in acid solution [19]. The calcium content increases by sedimentation but decreases in acid activation. Calcium is replaced by hydrogen ions. This is due to the reaction of impurities such as calcite that are removed by acid treatment. The sodium content decreases by sedimentation and acid activation. Figs 1 and 2 show the X-RD analysis of Azad Kashmir raw clay and the acid-activated clay. Fig. 1 shows that the raw clay

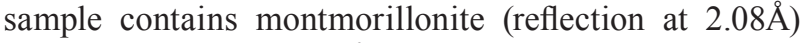
quartz (reflection at $3.35 \AA$ ) and additionally a few traces of illite clay (reflection at $1.54 \AA$ ). After purification and acid activation, the quartz peak is removed, and the longest peak is that of montmorillonite (reflection at

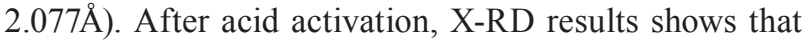
the interlayer structure of clay remains intact. Removal of the octahedral layer will result in collapse of the clay structure. However, a research study suggests that acid activation can partially dissolve the octahedral layer of clay due to partial dissolution of the octahedral sheets [19]. During acid activation, exchangeable ions in a clay matrix are replaced by protons, making clay more porous and enhancing surface area, and thus cationic exchange capacity.

\section{Optimization Studies}

\section{Effect of Adsorbent Quantity}

The amount of adsorbent determines its ability for a given initial concentration of the absorbate. Fig. 3 displays the influence of adsorbent amount on the adsorption of $\mathrm{Cd}$ (II) and $\mathrm{Pb}$ (II). The removal percentage of $\mathrm{Pb}$ (II) and $\mathrm{Cd}$ (II) increases with an incresae in the amount of clay. Higher amounts of clay for a fixed metal ion concentration provide large surface area or a larger number of adsorption sites, resulting in a higher capacity for adsorption [16]. The results show the removal efficiency of the two ions as they increase up to a certain point, beyond which an increase is insignificant.

\section{Effect of $p H$}

Fig. 4 shows the effect of $\mathrm{pH}$ on the adsorption of cadmium and lead on the acid-activated Azad Kashmir clay. As evidenced by the graphs, adsorption increases 


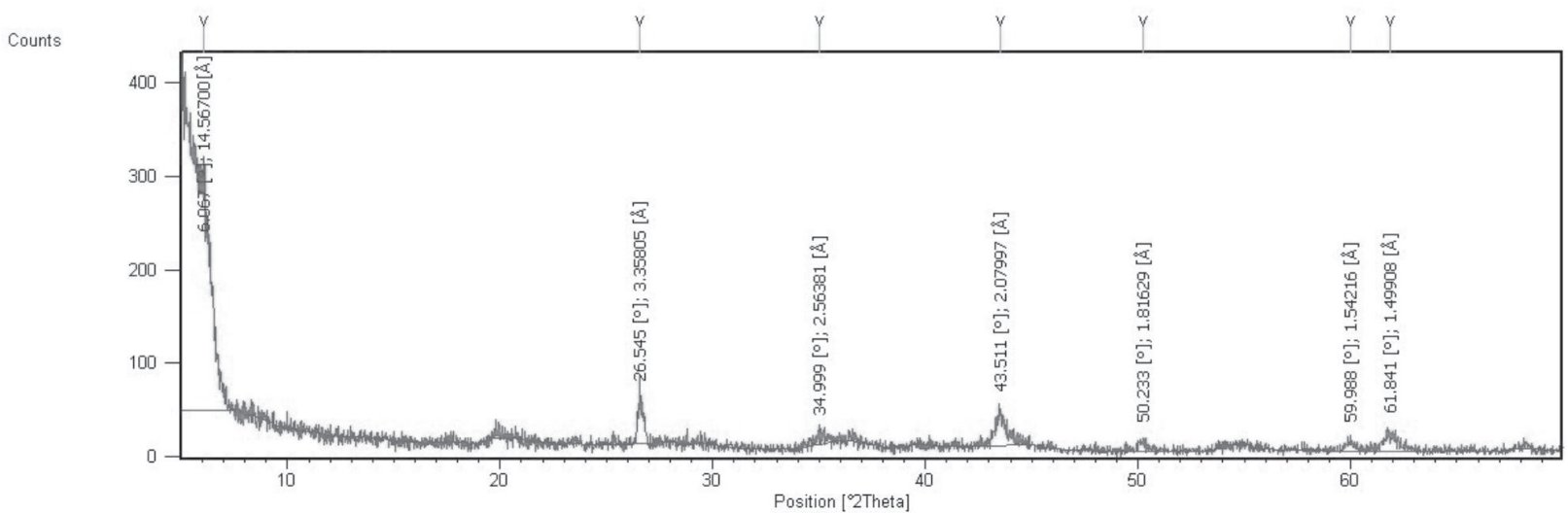

Fig. 1. X-RD of raw Azad Kashmir clay.

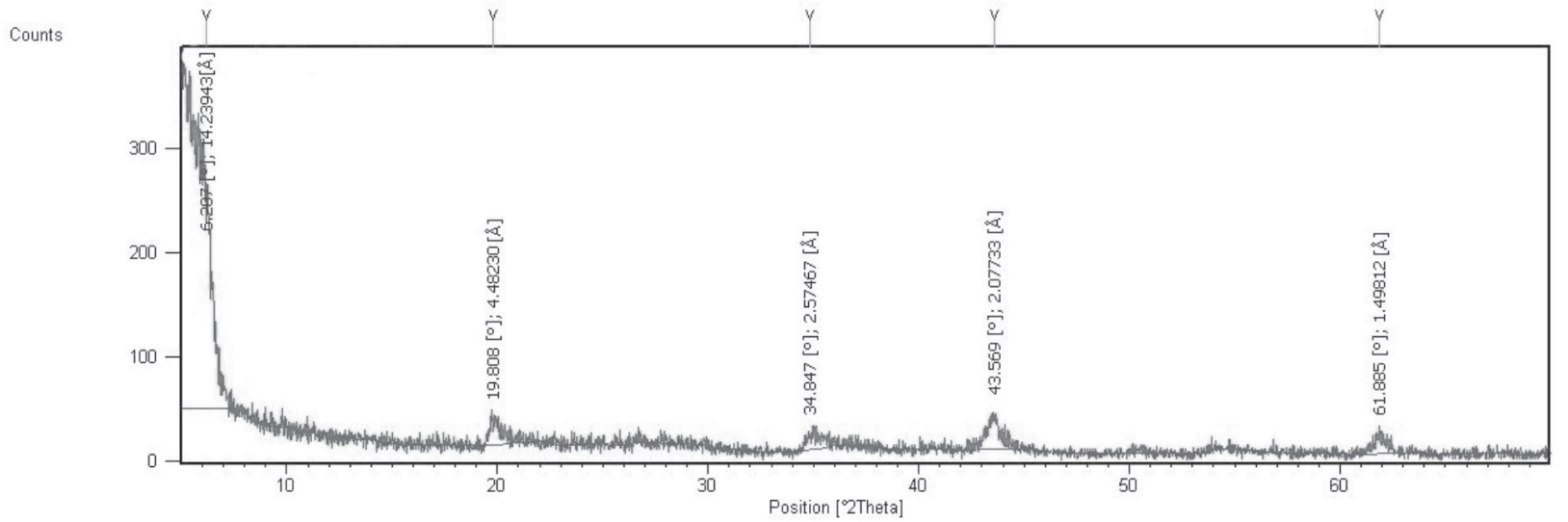

Fig. 2. X-RD of acid activated Azad Kashmir clay.

with the rise in $\mathrm{pH}$ of the solution for both elements. In the case of lead solution, no adsorption takes place at its original $\mathrm{pH}$ under normal conditions; however continuous rapid adsorption is seen with increases in $\mathrm{pH}$. Similarly, Cadmium ions are also effectively adsorbed by the acid-activated clay by increases in $\mathrm{pH}$ of the solution. This can be explained with

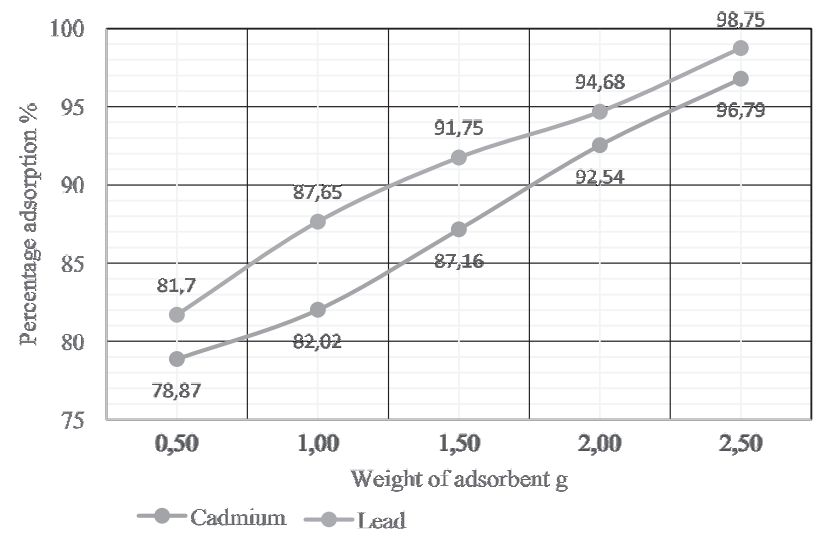

Fig. 3. Effect of weight of adsorbent on Cadmium \& Lead adsorption. montmorillonite clay containing a large number of active sites and becoming positively charged at low $\mathrm{pH}$, which results in the competition between the $\mathrm{H}^{+}$ and metal ions for available adsorption sites. Although there is an increase in $\mathrm{pH}$, this competition decreases as the surface becomes more negatively charged, which increases adsorption of all the elements.The $\mathrm{pH}$ of the

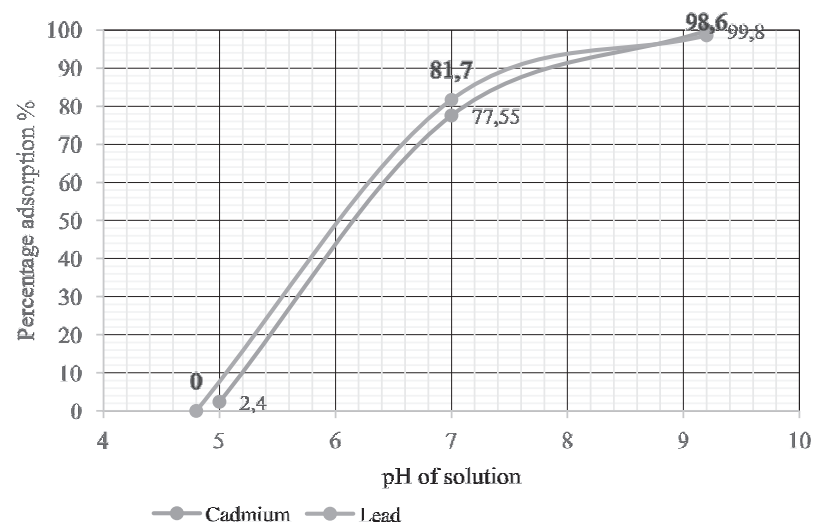

Fig. 4. Effect of $\mathrm{pH}$ on adsorption of Cadmium and Lead. 
Table 2. Langmuir adsorption constants for Cadmium and Lead.

\begin{tabular}{|c|c|c|c|c|c|c|c|}
\hline \multirow{3}{*}{ Metal } & $\begin{array}{c}\text { Temperature } \\
(\mathrm{K})\end{array}$ & $\begin{array}{c}\text { Slope } \\
1 / \mathrm{Qo}\end{array}$ & $\begin{array}{c}\text { Intercept } \\
1 / \mathrm{Qob}\end{array}$ & Qo & $\mathrm{b}$ & $\mathrm{R}^{2}$ & $\begin{array}{c}\text { Separation Factor } \\
\mathrm{R}_{\mathrm{L}}=1 /\left(1+\mathrm{b} \mathrm{C}_{\mathrm{i}}\right) \\
\mathrm{C}_{\mathrm{i}}=10\end{array}$ \\
\hline \multirow{3}{*}{ Cadmium } & $303(30)$ & 0.13 & 0.24 & 7.81 & 0.53 & 0.88 & 0.16 \\
\cline { 2 - 8 } & $313(40)$ & 0.13 & 0.27 & 7.73 & 0.47 & 0.86 & 0.17 \\
\cline { 2 - 8 } & $323(50)$ & 0.14 & 0.32 & 7.03 & 0.44 & 0.77 & 0.19 \\
\cline { 2 - 8 } & $303(30)$ & 0.25 & 2.2418 & 3.94 & 0.11 & 0.84 & 0.47 \\
\cline { 2 - 8 } & $313(40)$ & 0.30 & 1.9413 & 3.37 & 0.15 & 0.91 & 0.39 \\
\hline
\end{tabular}

aqueous solution significantly affects the adsorption of metal ion on the surface of adsorbent. The adsorption capacity metal ions onto adsorbent increases with the increasing $\mathrm{pH}$ value of aqueous solution [20].

\section{Adsorption Isotherms}

Langmuir and Freundlich adsorption isotherms are the most commonly used isotherms for the modeling of the batch adsorption process. The Langmuir adsorption isotherm has been used to illustrate many real adsorption processes. It proposes how adsorbate molecules are adsorbed by the adsorbent materials on a homogenous surface by monolayer without any interference of surrounding adsorbed molecules [21].

The Langmuir adsorption isotherm equation in its linear form is given by:

$$
\mathrm{Ce} / \mathrm{qe}=1 / \mathrm{Qob}+\mathrm{Ce} / \mathrm{Qo}
$$

...where b and Qo are Langmuir constants based on the energy of adsorption and adsorption capacity, Ce is equilibrium concentration $(\mathrm{mg} / \mathrm{l})$ of adsorbent and qe is the quantity of the adsorbed adsorbent at the time of equilibrium. Values of $b$ and Qo are determined from the slope and intercept of the plot of Ce/qe versus Ce. The Langmuir adsorption isotherm envisages the maximum monolayer adsorption capacity of the adsorbent and also establishes if the adsorption is favourable or not. The maximum adsorption capacities for cadmium and lead at different temperatures are given in Table 2. The adsorption capacity of various temperatures varies from 7.81-7.03 and 3.93-3.02 mg/g for cadmium and lead respectively. Various researchers have found the similar values for cadmium and lead adsorption capacities of different types of clays such as 7.56 and $4.50 \mathrm{mg} / \mathrm{g}$ on bentonite and kaolin respectively for lead [22]. Other researchers have reported similar values $(1.34 \mathrm{mg} / \mathrm{g}$ for $\mathrm{Pb}, 16.70 \mathrm{mg} / \mathrm{g}$ for $\mathrm{Pb}$ and 9.9 $\mathrm{mg} / \mathrm{g}$ for Cd (II) respectively) for adsorption capacities of cadmium and lead ions on various types of raw and modified clays [23]. The adsorption capacity of cadmium is greater compared to lead, which might be due the charge properties like ionic radius. Lead due to the high ionic radius and bulkier molecule is difficult to adsorb as compared to cadmium, which has lower molecular weight and low ionic radius as compared to lead. The experimental data for the research conducted for this paper is comparable with results found by other researchers.

The value of $b$ is also used to calculate the dimensionless constant known as separation factor $R_{L}$. $R_{L}$ values of less than 1 correspond to a favourable adsorption process. The separation parameter values of RL were computed. The values for cadmium and lead were found to be within the range of $0.15-0.18$ and 0.36-0.46, respectively. These values indicated $(0<\mathrm{RL}<1)$ that the adsorption processes for both metals are favourable in nature.

Table 3. Freundlich adsorption constants for Cadmium and Lead.

\begin{tabular}{|c|c|c|c|c|c|c|}
\hline \multirow{2}{*}{ Metal } & \multirow{2}{*}{ Temperature (K) } & Slope & \multirow{2}{*}{$\begin{array}{c}\text { Intercept log } \\
\mathrm{K}_{\mathrm{F}} \\
\end{array}$} & \multirow{2}{*}{$\mathrm{R}^{2}$} & \multirow{2}{*}{$\mathrm{n}$} & \multirow{2}{*}{$\mathrm{K}_{\mathrm{F}}$} \\
\hline & & $1 / \mathrm{n}$ & & & & \\
\hline \multirow{3}{*}{ Cadmium } & 303 & 3.90 & -4.39 & 0.97 & 0.26 & 0.012 \\
\hline & 313 & 3.39 & -3.48 & 0.96 & 0.30 & 0.031 \\
\hline & 323 & 3.26 & -3.02 & 0.93 & 0.31 & 0.048 \\
\hline \multirow{3}{*}{ Lead } & 303 & 0.34 & -0.34 & 0.93 & 2.95 & 0.714 \\
\hline & 313 & 0.41 & -0.45 & 0.98 & 2.43 & 0.641 \\
\hline & 323 & 0.29 & -0.20 & 0.95 & 3.41 & 0.817 \\
\hline
\end{tabular}


Table 4. Values of Gibb's free energy $(\Delta \mathrm{G})$, enthalpy change $(\Delta \mathrm{H})$ and entropy change $(\Delta \mathrm{S})$ for Cadmium and Lead.

\begin{tabular}{|c|c|c|c|c|c|c|}
\hline Metal & $\begin{array}{c}\text { Temperature } \\
\text { (K) }\end{array}$ & $1 / \mathrm{T}$ & $\operatorname{lnb}$ & $\Delta \mathrm{G}$ & $\Delta \mathrm{H}$ & $\Delta \mathrm{S}$ \\
\hline \multirow{3}{*}{ Cadmium } & 303 & 0.0033 & 0.6423 & -1.62 & & \\
\hline & 313 & 0.0032 & 0.7476 & -1.95 & 7.23 & 29.27 \\
\hline & 323 & 0.0031 & 0.8196 & -2.20 & & \\
\hline \multirow{3}{*}{ Lead } & 303 & 0.1133 & 0.0033 & -5.48 & & \\
\hline & 313 & 0.1529 & 0.0032 & -4.89 & 17.97 & 41.32 \\
\hline & 323 & 0.1760 & 0.0031 & -4.67 & & \\
\hline
\end{tabular}

Both Langmuir and Freundlich adsorption models were applied to the adsorption data. Both the models fit the data very well. The best numerical fit of the data was obtained by the Freundlich adsorption model showing regression coefficient values $\mathrm{R}^{2}>0.9$. The Freundlich model is applied to the adsorption at heterogeneous sites on the surface of the solids. The Freundlich adsorption isotherm is applicable for a reaction where heterogeneous adsorption reactions result in a multilayer formation [21]. Table 3 presents the results for the constants of Freundlich adsorption isotherm at different temperatures. The Freundlich adsorption constants $\mathrm{K}_{\mathrm{F}}$ and $\mathrm{n}$ describes the adsorption process such as adsorption capacity and adsorption intensity. If the adsorption intensity given by Freundlich coefficient $\mathrm{n}$ is less than 1 , it indicates that adsorption onto the adsorbent is favourable under studied conditions [23]. The results shown in Table 3 further support the evidence for enhanced adsorption for cadmium compared to lead.

\section{Thermodynamic Properties of the Adsorption Process}

In order to assess the thermodynamic feasibility of the process and to verify the nature of the adsorption process thermodynamic constants, Gibb's free energy $\left(\Delta G^{o}\right)$, enthalpy change $\left(\Delta H^{\circ}\right)$ and entropy change $\left(\Delta S^{\circ}\right)$ were computed for temperature T. Gibbs free energy of the process is related to the Langmuir equilibrium constant by the equation:

$$
\Delta \mathrm{G}^{0}=-\mathrm{RT} \operatorname{lnb}
$$

The Gibb's free energy change is interrelated with the enthalpy change $\left(\Delta \mathrm{H}^{\circ}\right)$ and entropy change $\left(\Delta \mathrm{S}^{\circ}\right)$ as:

$$
\ln \mathrm{b}=\Delta \mathrm{S}^{0} / \mathrm{R}-\Delta \mathrm{H}^{0} / \mathrm{RT}
$$

Table 4 provides the values of $\Delta \mathrm{G}^{\mathrm{o}}, \Delta \mathrm{H}^{0}$, and $\Delta \mathrm{S}^{0}$. The negative $\Delta \mathrm{G}^{\mathrm{o}}$ value established the achievability of the sorption process and the spontaneous character of adsorption. The positive value of $\Delta \mathrm{H}^{\mathrm{o}}$ obtained showed the endothermic nature of the process. The positive $\Delta S^{o}$ value showed the attraction of the adsorbent with
Cadmium and Lead. Similar observations have been reported by other researchers for clay adsorbents. Gibbs free energy values for Cadmium adsorption on acidactivated Azad Kashmir clays were calculated to be $-1.62,-1.95$ and $2.20 \mathrm{KJ} / \mathrm{mole}$ at temperatures of 303 , 313 and $323 \mathrm{~K}$, respectively. A decrease in the values of Gibbs free energy accompanied by an increase in temperature describes the decline in adsorption at high temperature. Slightly lower values of Gibbs free energy $-5.48,-4.89$ and $-4.66 \mathrm{KJ} /$ mole for 303,313 and $323 \mathrm{~K}$, respectively were obtained for lead $(\mathrm{Pb})$ adsorption. Similar results are reported by other researchers who calculated adsorption of $\mathrm{Pb}$ (II) on MX-80 bentonite between the temperature range of $291-328 \mathrm{~K}$ with $\Delta G$ increasing from -16.69 to $-16.57 \mathrm{~kJ} /$ mol [24].

A study conducted on adsorption of cadmium and lead ions on magnoxide minerals reports that the values of $\Delta \mathrm{G}$ decrease from -21.33 to $-22.87 \mathrm{KJ} / \mathrm{mole}$ for cadmium and -27.69 to $-29.84 \mathrm{KJ} /$ mole for lead between temperatures of $298-318^{\circ} \mathrm{K}$ [25]. Another study shows that values of $\Delta \mathrm{G}$ decrease from 7.95 to $7.31 \mathrm{KJ} / \mathrm{mole}$ for lead on activated clays between temperatures of 293-313K [26].

\section{Conclusions}

This study proposes a cost-effective solution for pollution remediation using locally available Azad Kashmir bentonite clay. This clay was purified, activated with acid treatment and then utilized for adsorption study of $\mathrm{Cd}$ (II) and $\mathrm{Pb}$ (II) ions in solution. The results were further analyzed by applying Freundlich and Langmuir adsorption isotherms. The Freundlich isotherm offers a better fit than the Langmuir adsorption isotherm for both $\mathrm{Cd}$ (II) and $\mathrm{Pb}$ (II) ions. This shows that ion exchange is a favorable and major process for eliminating $\mathrm{Cd}$ (II) and $\mathrm{Pb}$ (II) ions in solution by activated clay. The negative values of $\Delta \mathrm{G}$ indicate that adsorption processes are spontaneous and endothermic. These observations help to establish effective removal of $\mathrm{Cd}$ (II) and $\mathrm{Pb}$ (II) ions in solution in considerable quantities by the activated Azad Kashmir Clay from wastewaters. 


\section{Acknowledgements}

This research was carried out as part of the research and development program of the University of the Punjab, Lahore, in collaboration with that Pakistan Council of Scientific and Industrial Research Laboratories Complex, Lahore (PCSIR), Pakistan.

\section{Conflict of Interest}

The authors declare no conflict of interest.

\section{References}

1. NAFEES M., WASEEM A., KHAN A. Comparative Study of Laterite and Bentonite Based Organoclays: Implications of Hydrophobic Compounds Remediation from Aqueous Solutions. Sci. World. J. 2013, 2013.

2. GUPTA V., NAYAK A., BHUSHAN B., AGARWAL, S. A Critical Analysis on the Efficiency of Activated Carbons from Low-Cost Precursors for Heavy Metals Remediation. Crit. Rev. Environ. Sci. Technol. 45, 613, 2014.

3. INYANG I.M., GAO B., YAO Y., XUE Y., ZIMMERMAN A., MOSA A., PULLAMMANAPPALLIL P., OK Y.S., CAO X. A review of biochar as low-cost cost adsorbent for aqueous heavy metal removal. Crit. Rev. Environ. Sci. Technol. 46 (4), 406, 2016.

4. WASEEM A., ARSHAD J., IQBAL F., SAJJAD A., MEHMOOD Z., MURTAZA G. Pollution Status of Pakistan: A Retrospective Review on Heavy Metal Contamination of Water, Soil, and Vegetables. BioMed. Res. Int. 2014, 2014.

5. ARBABI M., HEMATI S., AMIRI M. Removal of lead ions from industrial wastewater: Removal methods review. Int. J. Epidemiol. Res. 2 (2), 105, 2015.

6. DIMPE K.M., NGILA J.C., NOMNGONGO P.N. Application of waste tyre-based activated carbon for the removal of heavy metals in wastewater. Cogent. Eng. 4 (1), $1330912,2017$.

7. KHAN S., SHAMSHAD I., WAQAS M., NAWAB J., MING L. Remediating industrial wastewater containing potentially toxic elements with four freshwater algae. Ecol. Eng. 102, 536, 2017.

8. IHSANULLAH, AL-KHALDI F.A., ABUSHARKH B., KHALED M.A., ATIEH M.A., NASSER M.S., LAOUI T., SALEH T.A., AGARWAL S., TYAGI I., GUPTA V.K. Adsorptive removal of cadmium (II) ions from liquid phase using acid modified carbon-based adsorbents. J. Mol. Liq. 204, 255, 2015.

9. SWARNALATHA K., AYOOB S. Adsorption studies on coir pith for heavy metal removal. I. J. S. Eng. 9, 259 , 2016.

10. AL-QODAH Z., AL-SHANNAG M. Heavy metal ions removal from wastewater using electrocoagulation processes: A comprehensive review. Sep. Sci. Tchnol. 52 (17), 2649, 2017.
11. MISHRA S.P. Adsorption-Desorption of Heavy Metal Ions. Curr, Sci. 107, 601, 2014.

12. UÇAR S., ERDEM M., TAY T., KARAGÖZ S. Removal of lead (II) and nickel (II) ions from aqueous solution using activated carbon prepared from rapeseed oil cake by $\mathrm{Na}_{2} \mathrm{CO}_{3}$ activation. Clean. Technol. Envir. 17 (3), 747, 2014.

13. ZHAO Y., YANG S., DING D., CHEN J., YANG Y., LEI Z., FENG C., ZHANG Z. Effective adsorption of Cr (VI) from aqueous solution using natural Akadama clay. J. Colloid. Interface. Sci. 395, 198, 2013.

14. BHATTACHARYYA K.G., GUPTA S.S. Removal of $\mathrm{Cu}$ (II) by natural and acid-activated clays: An insight of adsorption isotherm, kinetic and thermodynamics. Desalination. 272 (1-3), 66, 2011.

15. CHICINAŞ R.P., TĂNASE A., BEDELEAN H., MĂICĂNEANU A. Characterization of Romanian Bentonitic Clays for the Removal of Dyes from Wastewater, Anal. Lett. 49, (16), 2686, 2016.

16. YUSUF M.A., IQBAL M.M., RAFIQ M., AYUB M. Characteristics of Fuller's Earth of D.G. Khan. Pak. J. Sci. Ind. Res. 32, 789, 1989.

17. PANSU M., JACQUES Gautheyrou. Handbook of Soil Analysis: Mineralogical, Organic, and Inorganic Methods, Springer-Verlag, Berlin, Heidelberg, 2006.

18. YUSUF M., CHAUDHRY M.R. Activation of D.G. Khan Fuller's Earth with Hydrochloric Acid. Pak. J. Sci. Ind. Res. 41, 132, 1998.

19. AMARI A., GANNOUNI H., KHAN M.I., ALMESFER M.K., ELKHALEEFA A.M., GANNOUNI A. Effect of Structure and Chemical Activation on the Adsorption Properties of Green Clay Minerals for the Removal of Cationic Dye. Appl. Sci. 8, 2302, 2018.

20. GEORGESCU A.M., NARDOU F., ZICHIL V., NISTOR D.A. Adsorption of lead (II) ions from aqueous solutions onto Cr-pillared clays. Appl. Clay. Sci. 152, 44, 2017.

21. ULLAH H., NAFEES M., IQBAL F., AWAN M.S., SHAH A., WASEEM A. Adsorption Kinetics of Malachite Green and Methylene Blue from Aqueous Solutions Using Surfactant-modified Organoclays. Acta. Chim. Slov. 64, 449, 2017.

22. ABOLLINO O., ACETO M., MALANDRINO M., SARZANINI C., MENTASTI E. Adsorption of heavy metals on Na-montmorillonite. Effect of $\mathrm{pH}$ and organic substances. Water. Res. 37, 1619, 2003.

23. KULA R., KOYUNCU H. Adsorption of $\mathrm{Pb}$ (II) ions from aqueous solution by native and activated bentonite: Kinetic, equilibrium, and thermodynamic study. J. Hazard. Mater. 179, 332, 2010

24. GUPTA S.S., BHATTACHARYYA K.G. Removal of Cd (II) from aqueous solution by kaolinite, montmorillonite and their poly (oxo zirconium) and tetrabutylammonium derivatives. J. Hazard. Mater. 128, 247, 2006.

25. POTGIETER J.H., POTGIETER-VERMAAK S.S., KALIBANTONGA P.D. Heavy metals removal from solution by palygorskite clay. Miner. Eng. 19, 463, 2006.

26. SÖNMEZAY A., ÖNCEL M. S., BEKTAŞ N. Adsorption of lead and cadmium ions from aqueous solutions using manganoxide minerals. Trans. Nonferrous Met. Soc. China. 22, 3131, 2012. 
